\title{
A twenty-four year experience of autologous stem cell transplantation for light chain amyloidosis patients in the United Kingdom
}

Faye A Sharpley, ${ }^{1}$ Aviva Petrie,${ }^{2}$ Shameem Mahmood, ${ }^{1}$ Sajitha Sachchithanantham, ${ }^{1}$ Helen J

Lachmann, ${ }^{1}$ Julian D Gillmore, ${ }^{1}$ Carol J Whelan, ${ }^{1}$ Marianna Fontana, ${ }^{1}$ Ana Martinez De Azcona

Naharro, ${ }^{1}$ Cristina Quarta, ${ }^{1}$ Philip N Hawkins, ${ }^{1}$ and Ashutosh D Wechalekar ${ }^{1}$

${ }^{1}$ National Amyloidosis Centre, University College London, London, UK

${ }^{2}$ Biostatistics Unit, UCL Eastman Dental Institute, London, UK

Short title: ASCT is an increasingly safe treatment for AL amyloidosis

\section{Author correspondence:}

Professor Ashutosh Wechalekar

National Amyloidosis Centre,

University College London (Royal Free Campus)

Rowland Hill Street

London, UK

02074332758

a.wechalekar@ucl.ac.uk

Word count: summary-200, main text-4437, methods- 619 , tables-5, figures- 3,1 supplementary file

\section{Acknowledgements:}

We would like to thank all the patients, clinical and nursing staff at the National Amyloidosis Centre.

FAS and AW conceived the study, FAS, AP and ADW analysed the data and wrote the manuscript.

AP, SM, SS, HJL, JDG, CJW, MF, AM, CQ, PNH and ADW all contributed to the manuscript and provided substantial critical input. All authors provided substantial contributions to the paper and have reviewed the final version of the manuscript.

Conflict of interest statement: the authors have no conflicts of interest to disclose. 


\section{Summary}

Autologous stem cell transplantation (ASCT) is considered to be the best method to achieve deep hematological/organ responses and improve survival in selected patients with AL amyloidosis. This field has been led by US centres and is less utilised in Europe. The introduction of effective chemotherapy agents for AL has prompted us to re-evaluated UK outcomes of ASCT. A total of 264 AL amyloidosis patients treated with an ASCT 1994-2018 were identified. Patient baseline characteristics, transplant related mortality (TRM) and overall survival (OS) were analysed. The median OS post ASCT was 87 months (95\% CI: 77-106 months). The median time from ASCT to next treatment was 48 months (95\% CI: 29-55 months). A haematological response was achieved in $94.8 \%$ of patients and was a strong predictor of time to next treatment $(\mathrm{p}<0.0001, \mathrm{HR}=1.75, \mathrm{CI}=1.35-2.28)$ and $\mathrm{OS}(\mathrm{p}=0.007, \mathrm{HR}=1.91, \mathrm{CI}=1.19-3.07)$. Organ response was: $\operatorname{cardiac}(\mathrm{n}=28,60.9 \%)$, renal $(\mathrm{n}=101$, $76 \%$ ) and liver $(\mathrm{n}=7,13.5 \%)$. Overall TRM was $8.7 \%$, with a significant reduction over time (19942000: $18.8 \%$; 2001-2006: $13.6 \% ; 2007-2012: 6.2 \% ; 2013-2018: 1.1 \%)$. In conclusion, ASCT is significantly safer and remains a highly effective treatment with excellent long term survival. ASCT should be more widely considered as a treatment option for systemic AL amyloidosis.

Key words: AL amyloidosis, autologous stem cell transplant, transplant related mortality, survival outcomes, organ response. 


\section{Introduction}

Systemic amyloidosis (AL) is a multi-system disorder characterised by tissue deposition of amyloidogenic light chains as amyloid fibrils resulting in progressive organ dysfunction and reduced survival. In the majority of cases, the condition is caused by an underlying plasma cell clone, similar to monoclonal gammopathy of uncertain significance or multiple myeloma (MM). The standard treatment is anti-plasma cell chemotherapy. High dose myeloablative chemotherapy, as part of an autologous stem cell transplant (ASCT), remains the standard of care for younger/fitter patients with MM with the potential for improved survival and a prolonged treatment free interval, and has been used for patients with AL for nearly 20 years.(Comenzo, et al 1996) However, ASCT is not without risk even for uncomplicated MM patients with a $2.5 \%$ overall transplant related mortality (TRM). (Thidemann Andersen, et al 2017) The risk of TRM is even higher for AL amyloidosis patients given the involvement of the heart, kidneys, liver and gastrointestinal tract. A TRM figure reaching $43 \%$ was reported during the early years of ASCT in AL reflecting the risk of multi-organ failure, sudden cardiac death, gastrointestinal haemorrhage and sepsis.(Moreau, et al 1998) Over the last two decades a combination of stringent patient selection (Venner, et al 2014), and increased transplant experience, has significantly reduced the TRM for AL amyloidosis patients to 7\% (Oke, et al 2017). This is associated with a 5 and 10 year survival rate of $80 \%$ and $60 \%$ respectively for those patients who achieve a haematological response (HR) to ASCT.(Sanchorawala, et al 2015) (Sidiqi, et al 2018) However, in 2007, a pivotal French randomised trial reported that standard dose chemotherapy was non-inferior to ASCT.(Jaccard, et al 2007) There has been some criticism of this data due to inclusion of patients with cardiac involvement and associated high TRM. Over the decades, due to the complexity of patient selection, level of experience of the transplant centre and availability of high effective novel agent chemotherapy, ASCT has remained controversial in AL amyloidosis.

Due to previous concerns of TRM, ASCT, particularly upfront ASCT, is much less common in patients with AL amyloidosis in the UK. Less than 5\% of patients are treated with an ASCT in UK, although $10-15 \%$ would be potentially eligible.(Manwani, et al 2018) This is in stark contrast with data from the US, where approximately a third of patients are treated with an ASCT.(Muchtar and Gertz 2017) Over a ten year period, 1994-2004, a total of 92 patients were treated with an ASCT in 
the UK (out of a total of over 1500 patients seen); (Goodman, et al 2006) this compares with 421 patients treated at a single US centre in Boston over a similar period.(Cibeira, et al 2011) Our UK analysis (2003-2012) also suggested that an improvement in TRM lagged behind that of the US (6.8\% vs $5 \%$ in the UK and US respectively).(Gertz, et al 2013, Venner, et al 2014) Since this last analysis (Venner, et al 2014) multiple highly effective bortezomib based chemotherapy combinations have been introduced with a corresponding improvement in the survival outcomes for patients with $\mathrm{AL}$ amyloidosis.(Muchtar and Gertz 2017) This has prompted this retrospective analysis of the TRM as well as long-term survival outcomes of all patients with AL amyloidosis patients treated with an ASCT over a twenty-four year period (1994-2018). Our aim was to analyse survival outcomes in time cohorts to assess if there has been an improvement in TRM and survival outcomes over time. 


\section{Methods}

The National Amyloidosis Centre provides a tertiary referral service for patients with amyloidosis and related disorders in the UK. The target population is all English and Scottish patients with both suspected and histologically demonstrated amyloidosis.(Pinney, et al 2013) We searched our database of 5,112 patients for all patients treated with an ASCT from 1994-2018. Patients were excluded if they were treated with an ASCT prior to their diagnosis with AL amyloidosis, or if they were treated with a second ASCT. Patients were analysed as an entire cohort, and then by four time cohorts, determined by the date of ASCT: group 1: 1994-2000, group 2: 2000-2006, group 3:2007-2012 and group 4: 20132018; these intervals were associated with significant changes in treatment paradigms for AL amyloidosis and are similar to those reported by colleagues in the US.(D'Souza, et al 2015) A diagnosis of amyloidosis was confirmed by Congo red staining of a tissue biopsy with demonstration of characteristic birefringence under cross-polarized light. The amyloid subtype was confirmed by immunohistochemistry with specific antibodies, or by mass spectrometry.(Rezk, et al 2019) Hereditary amyloidosis was excluded by gene sequencing as appropriate. All patients had a detailed baseline assessment of organ function with biomarker assessments and imaging including SAP scintigraphy. Organ involvement was defined according to the international amyloidosis consensus criteria.(Gertz, et al 2005) We recorded any treatment given prior to the stem cell transplant, in addition to the ASCT conditioning regimen. Haematological response was assessed at six months. Due to the lag in organ response, organ responses were assessed at 12 months. Both were calculated from the date of the ASCT and defined according to the international amyloidosis consensus criteria.(Gertz, et al 2005) For the time cohorts prior to 2012 (group 1: 1994-2000, group 2: 2000-2006, and a few patients in group 3: 2007-2012), haematological response was evaluated using the paraprotein (M protein) in cases where a serum free light chain (FLC) analysis was not available, as per the 2005 consensus criteria.(Gertz, et al 2005) Cardiac response by biomarkers was not evaluable for cohorts 1 and 2 as $\mathrm{N}$-terminal B natriuretic peptide (NT-proBNP) levels have only been routinely assessed in our center since 2007 . The primary outcome was TRM and overall survival (OS) following ASCT, defined as time from ASCT to death. TRM was defined as all-cause mortality before day +100 , calculated from the return of stem cells, to allow a direct comparison with previous UK studies.(Goodman, et al 2006, Venner, et al 2014). 
Survival from the date of diagnosis with amyloidosis was also calculated. Secondary outcomes included: time to next treatment (defined from date of ASCT to the start of next treatment) and haematologic responses to ASCT as well the impact of depth of response on survival.

Statistical analysis was performed using SPSS (IBM Corp. Released 2012. IBM SPSS Statistics for Windows, Version 21.0. Armonk, NY: IBM Corp).and Stata (StataCorp. 2017. Stata Statistical Software: Release 15. College Station, TX: StataCorp LLC). The distribution of each numerical variable across the time cohorts was compared using the Kruskal-Wallis test. If significant, this was followed by Bonferroni corrected pairwise comparisons. The Chi-squared or Fisher's exact test, as appropriate, was used for categorical variables. A trend analysis was performed, to assess change across time, using the Spearman rank correlation coefficient for categorical variables and Cuzick's nonparametric test for numerical variables. Creatinine and NT-proBNP were analysed after logtransformation to normalise the distribution of these continuous variables. The Cox proportion hazards model on the entire cohort was used to assess predictors of OS and TTNT with the assumption of proportional hazards verified. Univariable Cox regression analyses were followed by a multivariable Cox model including all those variables significant at the $10 \%$ level. Kaplan-Meier survival curves were drawn. A significance level of 0.05 was used for all hypothesis tests. Approval for analysis and publication was obtained from the institutional review board at the University College London, and written consent was obtained from all patients in accordance with the Declaration of Helsinki. 


\section{Results}

Two hundred and sixty four patients were identified. The patient characteristics are outlined in Table

1. The number of new cases of AL amyloidosis was available for the last two time cohorts. In 20072012, 4\% of all new patients with AL amyloidosis received a transplant $(\mathrm{n}=65 / 1480)$ and in 2013-2018 ( $\mathrm{n}=91 / 2060) 4 \%$ of all new cases of AL amyloidosis patients were transplanted.

\section{Differences in patient and disease characteristics across the time cohorts}

The variables that significantly differed across the time cohorts were: age at time of ASCT, time from diagnosis with amyloidosis to date of ASCT, number of organs involved with amyloidosis, baseline creatinine, albumin, proteinuria, bilirubin, alkaline phosphatase (ALP) and the number of lines of chemotherapy treatment prior to ASCT. Pairwise comparisons, with each variable taken as the outcome, were then used to identify the time cohorts between which the variables differed significantly (see Appendix, Table 6). Patients in the latter two time cohorts (median age 60 years and 58 years for cohorts 3 and 4 respectively) were significantly older at time of transplant than the earlier cohorts (median age 53 years for cohorts 1 and 2). The performance status of transplanted patients also significantly differed over time; the majority of patients in cohort $1(n=29,45.3 \%)$ and cohort $2(n=22$, $50 \%$ ) were Eastern Cooperative Oncology Group (ECOG) category 0, compared with the latter cohorts where the majority of patients were ECOG 1 (cohort $3, n=43,66.2 \%$ and cohort $4, n=45,49.5 \%$ ). A major difference was that in the latter two cohorts, compared with the first two time cohorts, a higher proportion of patients had received some chemotherapy prior to proceeding to transplant ( $81 \%$ and $88 \%$ vs. $57 \%$ and $0 \%$ respectively Kruskal-Wallis $\mathrm{P}<0.001$ ). This was also reflected in a difference in the time from diagnosis with amyloidosis to ASCT, which was a median of 7.5 months in cohort 1 vs. 13 months (Kruskal-Wallis $\mathrm{P}=0.001$ ) for cohort 3, and 14 months for cohort 4 (Kruskal-Wallis $\mathrm{P}=0.002$ ).

A full list of the variables that differed across time cohorts, the cohorts between which the variable differed and the corresponding $\mathrm{P}$ values for this difference are provided in appendix table 6.

\section{Pre-ASCT treatment, stem cell mobilisation and conditioning regimen}

Eighty patients $(n=80,30 \%)$ had an up-front ASCT, 59\% $(n=47 / 80)$ of which were in the first cohort (1994-2000). The majority of patients had their ASCT after first line treatment $(n=118,45 \%)$. The 
most frequently used regimen pre-ASCT was a Bortezomib based regimen $(\mathrm{n}=83,51.8 \%)$, followed by Thalidomide ( $\mathrm{n}=58,36.3 \%)$. A combination of cyclophosphamide and G-CSF was used to mobilise stem cells for the majority of patients in the early cohort. In the later cohorts, G-CSF alone was used, following publication of the review by Comenzo and Gertz in Blood (Comenzo and Gertz 2002). Due to the retrospective nature of this study, full details of the individual patient mobilisation regimes were lacking.

A reduced melphalan conditioning dose of $140 \mathrm{mg} / \mathrm{m}^{2}$ was used in $43 \%$ of patients $(n=80 / 186)$ (melphalan dose details were not available in 72 cases) and six patients (3\%) received an alternative conditioning regimen with carmustine, etoposide, cytarabine and melphalan (BEAM). A significant difference in the conditioning regimen was only seen between the earliest two cohorts, with a dose reduction used in $28.6 \%$ vs $62.5 \%$ in cohort 1 vs 2 respectively, Fisher's exact $\mathrm{p}=0.004$. There was no significant difference between patients treated with a full dose compared with reduced melphalan conditioning regimen in terms of: haematological (Fisher's exact p>0.999), organ responses, (cardiac, $\mathrm{p}>0.533$, renal $\mathrm{p}>0.134$ and liver $\mathrm{p}>0.097)$ and overall survival $(\mathrm{p}=0.301, \mathrm{HR}-1.278, \mathrm{CI}-0.801-2.041)$.

\section{Treatment related mortality (TRM)}

With a median follow-up of 68 months (range: 2-284 months), there were 106 deaths (40.2\%). For comparison with our previously published data (Venner, et al 2014 and Goodman, et al 2006)), we defined TRM as all-cause mortality before day +100 , calculated from the return of stem cells TRM was defined by death within 100 days of return of stem cells. The TRM for the entire cohort was $8.7 \%$ $(\mathrm{N}=23 / 264)$. The TRM significantly reduced over time, $18.8 \%$ vs $13.6 \%$ vs $6.2 \%$ vs $1.1 \%$ for cohorts $1,2,3$ and 4 respectively, $(\mathrm{P}=0.004, \mathrm{HR}=0.048, \mathrm{CI}=0.006-0.381)$.

\section{Response assessment}

Haematological responses are outlined in Table 2. Of the entire cohort of 264 patients $(88 \%$, $\mathrm{N}=236 / 264$ ) were evaluable (26 patients had died and five had missing reading). The responses were as follows: a complete response (CR) $(n=122,52 \%)$, a very good partial response (VGPR) $(n=40,17 \%)$, a partial response $(P R)(n=59,25 \%)$, no response $(N R)(n=10,4 \%)$ and progressive disease $(P D)(n=5$, $2 \%$ ). An overall haematological response (defined as a partial response or better) was seen in $95 \%$ of 
all cases $(n=221 / 233)$ and by subset analyses: cohort $1: 97 \%(n=44 / 46)$, cohort $2: 94 \%(n=33 / 35)$, cohort 3: $100 \%(n=65 / 65)$, cohort 4: $88 \%(n=79 / 90)$. An overall haematological response for cohorts 3 and 4 combined was achieved in 93\% of patients with CR: 50\% (n=77/155), VGPR: 21\% (33/155), PR: 22\% (34/155). The rates of VGPR/CR were greatest for cohorts $1(76 \%, n=35 / 46)$ and cohort $4(76 \%$, $\mathrm{n}=68 / 90)$ compared with cohorts $2(49 \%, \mathrm{n}=17 / 35)$ and cohort $3(65 \%, \mathrm{n}=42 / 65)$, but this may be biased (with a possible over representation of $\mathrm{CR}$ ) as a response assessment using serum free light chain was only possible in $59 \%(\mathrm{n}=27 / 46)$ of patients in this early cohort, with haematological response based on M-protein reduction in the remaining 41\% $(n=19 / 46)$. Organ responses at 12 months are outlined in table 2. Of the 85 patients with cardiac involvement, a cardiac response was evaluable at 12 months in $54 \%(\mathrm{n}=46 / 85)$, the remaining patients had died or had missing NT-proBNP values. A cardiac response was seen in $61 \%(n=28 / 46)$. Of the 180 patients with renal involvement $74 \%(n=133 / 180)$ were evaluable, the remaining 47 (26.1\%) of patients had died or had missing data. A renal response was seen in 76\% ( $n=101 / 133)$ of cases. Fifty-two patients had liver involvement and $60 \%(n=31 / 52)$ had data for an organ assessment at 12 months. The majority of patients had neither a liver response nor progression $(61 \%, \mathrm{n}=19 / 31)$.

\section{Overall Survival (OS)}

All survival analyses are with a cut-off of 150 months, given the low number of patients at risk beyond this time point. Separate analysis was done to identify survivors beyond 15 yrs. The median overall survival from diagnosis with AL amyloidosis was 99 months (95\% CI: 87-118 months) and by time cohort: cohort 1: 49 months (95\% CI: 15-69 months); cohort 2: 51 months (23-106 months); cohort 3: 137 months and cohort 4, not reached. The median OS from ASCT was 87 months (95\% CI: 77-106 months) for all patients and by time cohort: 60 months (95\% CI: 41-86 months) for cohorts 1 and 2 (95\% CI: 40-103 months) and not reached in the latter two cohorts (Fig. 1). The OS at 5, 8 and 10 years from diagnosis for the entire cohort was $74 \%$ (95\% CI: $67-79 \%$ ), $56 \%$ (95\% CI: $48-64 \%$ ) and $44 \%$ (95\% CI: 35-53\%), respectively. The 5 year survival for cohorts 3 and 4 were: $83 \%$ (95\% CI 72-90\%) and 90\% (95\% CI: 78-96\%), respectively. At 20 years from ASCT, 33\% of transplanted patients were alive (CI: 24-43\%). Haematological response was a strong predictor of outcome (Fig. 2), with a median OS of 139 months (95\% CI: 82-139 months) for patients who achieved a CR or VGPR compared with 
64 months (95\% CI: 50-92 months) for those in a PR, SD or PD at six months, $(\mathrm{P}=0.007, \mathrm{HR}=1.91$, $\mathrm{CI}=1.19-3.07)$.

We assessed the outcome of patients achieving a CR versus VGPR. There was no significant interaction between response and cohort $(\mathrm{P}>0.140)$, and so an analysis was performed with all the cohorts combined. There was no significant difference in the OS between those who achieved a CR vs VGPR $(\mathrm{p}=0.853, \mathrm{HR}=1.067, \mathrm{CI}=0.54-2.10) . \quad$ For the entire cohort the TTNT was a median of 48 months (95\% CI: 18-29 months) for the entire cohort. There was no significant impact of haematological response on TTNT when all cohorts were combined ( $\mathrm{p}=0.673, \mathrm{HR}-0.851, \mathrm{CI}=0.40-1.80)$, but there was a significant difference between patients who achieved a CR/ VGPR: 49 months (95\% CI: 24-48 months) compared with PR/SD/PD: 35 months (95\% CI: 9-20 months), p<0.0001, HR=1.75, CI=1.352.28) (Fig. 3). Further stratification showed median TTNT was: CR: 54 months (95\% CI: 4773months), VGPR: 73 months (95\% CI: 19- months), PR: 24 months (95\% CI: 12-35 months) and SD: not evaluable. The TTNT was apparently lower for CR than VGPR, but this may represent bias due to a lack of FLC measurements in the early cohorts.

Table 3 outlines the results of the univariable Cox regression analysis, looking for variables that were prognostic of OS post ASCT. The factors that significantly predicted survival at the $5 \%$ level $(\mathrm{P}<0.05)$ on univariable analysis were: performance status of 1 or above, the Mayo stage (2004) 2 or 3,(Dispenzieri, et al 2004) the number of organs involved with amyloidosis, cardiac involvement, gastrointestinal involvement (GI), liver involvement, left ventricular wall thickness (IVS), log-Nterminal B natriuretic peptide (NT-proBNP), log-creatinine, elevated ALP (defined as a value $>129$ IU/L) and having two lines of treatment prior to ASCT. The amyloid load on SAP scintigraphy (equivocal, small, moderate of large) was not significant at the 0.05 level $(\mathrm{P}=0.065, \mathrm{HR}=1.95, \mathrm{CI}=0.96$ 3.96). A multivariable model (Table 4) was produced by including all variables significant at the $10 \%$ level in the univariable analysis, except cardiac involvement, IVS, renal and liver involvement given the overlap of these variables with Mayo stage, ALP and creatinine. Independent predictors of OS on multivariable analysis were Mayo stage 2 or $3(\mathrm{P}=0.006, \mathrm{HR}=5.49, \mathrm{CI}=1.62-18.66))$, an abnormal ALP $(\mathrm{P}=0.003, \mathrm{HR}=6.96, \mathrm{CI}=1.90-25.51)$ and performance status $(\mathrm{P}=0.030, \mathrm{HR}=3.38, \mathrm{CI}=1.12-10.20)$.

\section{Discussion}


This study describes the outcome of 264 patients with AL amyloidosis from the UK treated with an ASCT over a 24-year period, 1994-2018. An improvement in the safety of ASCT is seen, with a significant reduction in TRM over time. The most recent cohort of patients had a haematological response rate of $88 \%$ and a 5 year OS of $90 \%$ suggesting that ASCT is not only an increasingly safe but highly efficacious treatment for AL amyloidosis patients.

ASCT has been utilised as a treatment for patients with AL amyloidosis for over two decades.(Comenzo, et al 1996) The high initial TRM of between 10-43\% (Moreau, et al 1998) resulted in efforts to better understand patient, disease and transplant related factors which may be linked to an increased risk of mortality. This has, to a large extent, been led by detailed analyses of the experience from large US transplant centres to identify factors that are predictive of TRM and has shaped global practice. One of the first longitudinal studies was performed by the Boston group. (Skinner, et al 2004) Unsurprisingly, cardiac involvement was identified as the main predictor of mortality in patients with AL amyloidosis undergoing ASCT.(Saba, et al 1999, Skinner, et al 2004) The number of visceral organs involved with amyloidosis and the serum creatinine at the time of transplantation were also found to be predictive of poor outcome.(Gertz, et al 2002) In 2002, the Mayo group combined these prognostic variables to categorise patients into good, intermediate and poor risk groups.(Comenzo and Gertz 2002) The Mayo staging system, outlined in 2004 and revised in 2012, prompted the refinement of this selection criteria (Kumar, et al 2012) and a cardiac troponin (cTNT) $>0.06 \mathrm{ng} / \mathrm{ml}$ or NTproBNP > 5000ngl were considered to be markers of high risk of early TRM.(Gertz, et al 2013) Our group have also identified: severe autonomic neuropathy, significant GI bleeding due to amyloidosis, advanced renal failure, age over 70 years, symptomatic recurrent amyloid related pleural effusions, a poor performance status $(\mathrm{ECOG}>2$ ) (Wechalekar, et al 2015) and nephrotic range proteinuria (Venner, et al 2014) factors predicting poorer outcomes after ASCT.

We were also able to study prognostic factors for OS in this study. Creatinine and the number of organs involved were significant on univariable but not subsequent multivariable analysis. Amyloid load by SAP scintigraphy scan was not significant on univariable analysis, but this may be as patients with a large amyloid load on SAP have been excluded from ASCT since the publication of our initial cohort 
(Goodman et al 2004) where a large amyloid load in SAP scintigraphy was identified as marker of poor outcome and high TRM. Cardiac involvement, particularly the severity as defined by the 2004 Mayo stage or by $\log$ NT-proBNP, was the most important predictor of survival on univariable and multivariable analyses in this study. The prognostic impact of Mayo staging is unsurprising and reinforces the critical utility of the Mayo staging system in stratifying patients, supporting its continued use to select patients for an ASCT.(Sher and Gertz 2017) An abnormal ALP was also prognostic on multivariable analyses. The Boston group found no increase in TRM in patients with hepatic involvement treated with ASCT.(Girnius, et al 2009) Others have identified liver involvement to be an independent predictor of mortality in AL.(D'Souza, et al 2015, Migrino, et al 2009). Confirmation of this finding is important since liver involvement has no place in current ASCT selection criteria.

The efforts from international centres, as well as our previous studies to carefully define factors that indicate increased risk of morbidity and mortality during ASCT, have resulted in progressively stringent patient selection. We confirm that this has significantly helped to reduce the TRM over time, from $18.8 \%$ in $1994-2000$ to $1.1 \%$ from $2013-2018$. This latest TRM compares favourably to a $2.4 \%$ TRM quoted by the US for the period 2010-2016 (D'Souza, et al 2015) and also to the $2.1 \%$ quoted in a recent nationwide study from the Danish Multiple Myeloma registry (Thidemann Andersen, et al 2017)for multiple myeloma treated with ASCT. Other factors which may have influenced the reduction in TRM seen over time include the use of routine broad spectrum gram negative prophylactic antibiotics, and that all patients considered for transplant in UK are reviewed at the national amyloidosis centre for suitability for transplantation, with a patient specific supportive care plan given, to help mitigate the risk associated with a small volume transplant centre. Both measures have been implemented as standardised care since the publication of the Venner et.al paper. (Venner, et al 2014)

The subset analyses of this study highlight how patient characteristics have changed over time. The median age at time of transplant has significantly increased over time. Rather than advancing age being protective against TRM, this may suggest that ASCT is increasingly being offered to older patients, perhaps reflecting increasing experience and confidence in ASCT. There was a significant trend away from transplanting patients in a poor performance category (28\% vs $12 \%$ of patients ECOG 2 or above 
in cohorts 1 vs 4 respectively, $\mathrm{P}=0.030$ ). Performance status is a known risk factor for TRM (Gertz, et al 2013) and this reinforces that performance status rather than age is a more reliable factor when determining whether an ASCT is appropriate. A study by the Boston group supports this finding and suggests that functional assessments, such as the six-minute walk test and cardiopulmonary exercise testing (CPET), should be included in the criteria to assess eligibility for ASCT.(White, et al 2018) Whilst the Mayo stage (or cardiac involvement) remained the strongest predictor of OS, the proportion of patients with cardiac involvement did not significantly differ over time in this study and, likewise, the proportion of patients in various Mayo stages did not significantly differ across the cohorts. The key difference was a very high proportion of patients in the latter cohorts had some prior chemotherapy. This may well work as a "stress test" for selecting patients as most of the early mortality in AL occurs in the first few months following diagnosis.(Muchtar and Gertz 2017)

In this current era of novel agent based therapy, the major advantage of ASCT is better long term outcomes. Our previous studies, possible tempered by higher TRM, seemed to suggest less long-term benefits of ASCT in the UK patient population compared to outcomes reported from large US series. This updated analysis of UK outcomes is very encouraging and suggests that outcomes of ASCT in are now internationally comparable (Table 5). The median OS for the entire UK cohort of 9.6 years is comparable to that reported by the Boston group over a similar 20 year period.(Sanchorawala, et al 2015) Our finding also supports that of the Boston and Mayo groups, that haematologic response to ASCT is an important predictor of outcomes as the median OS and TTNT in this study were significantly longer for patients who achieved a CR or VGPR compared with those who achieved a PR or were non-responders.

This study is not without its limitations. This is a retrospective study with data collected over a twentyfour year period. The National Amyloidosis Centre provides a tertiary referral service and so patients are highly selected by the requirement to attend. The referring local hospitals were the treating centres for the ASCT and so we were unable to reliably collect bone marrow plasma cell percentage, ASCT 
associated toxicity and supportive care data. The stem cell mobilisation regimen, and melphalan conditioning dose were also missing in a number of cases. Despite these limitations, this study of 264 AL amyloidosis patients treated with an ASCT represents the largest UK analysis of the long term survival outcomes to date.

There are still unanswered questions regarding ASCT for AL amyloidosis patients. Whether induction therapy is required for AL amyloidosis patients remains controversial. The majority of AL amyloidosis patients will have $10 \%$ or fewer clonal plasma cells within the marrow and so there is no need for 'induction' therapy or chemotherapy to 'debulk,' or reduce the plasma cell burden .(Comenzo and Gertz 2002) Upfront ASCT approach is frequently used in the US where $90 \%$ of patients have an ASCT within 12 months of diagnosis and 69\% within 6 months.(Sidiqi, et al 2018) The median time from diagnosis to ASCT in this study was 12 months and ASCT was most commonly following chemotherapy. There was also a notable trend in this study away from up-front ASCT, with an increasing median time from diagnosis to ASCT. Superior haematological response rates, PFS and OS have been reported with immunomodulatory/ proteasome inhibitor therapy prior to ASCT.(Afrough, et al 2018, Sanchorawala, et al 2011) This trend towards giving chemotherapy prior to ASCT may help towards explaining the decreased TRM and raises a critical question: should the field move away from upfront transplants for AL in favour of pre-treating prior to transplant? We recently reported the efficacy and safety of 'truly' deferred ASCT.(Manwani, et al 2018) This method permits substantial organ recovery prior to transplant and may allow more patients to be eligible for this effective treatment option, but this requires further exploration.

In conclusion, this study of 264 patients with AL amyloidosis treated with an ASCT over a 24-year period confirms the improved safety of this treatment over time, with figures comparable to contemporary international data. This study supports, and encourages, the use of ASCT for patients with AL amyloidosis. The current analysis confirms the validity of section criteria and suggests that Mayo stage, liver involvement and performance status are particularly important criteria for selecting 
patients eligible for this procedure. Patients who achieve a deep haematological response to ASCT appear to benefit the most with a prolonged clinical remission and excellent long term survival outcomes. 


\section{References}

Afrough, A., Saliba, R.M., Hamdi, A., Honhar, M., Varma, A., Cornelison, A.M., Rondon, G., Parmar, S., Shah, N.D., Bashir, Q., Hosing, C., Popat, U., Weber, D.M., Thomas, S., Orlowski, R.Z., Champlin, R.E. \& Qazilbash, M.H. (2018) Impact of Induction Therapy on the Outcome of Immunoglobulin Light Chain Amyloidosis after Autologous Hematopoietic Stem Cell Transplantation. Biol Blood Marrow Transplant, 24, 2197-2203.

Cibeira, M.T., Sanchorawala, V., Seldin, D.C., Quillen, K., Berk, J.L., Dember, L.M., Segal, A., Ruberg, F., Meier-Ewert, H., Andrea, N.T., Sloan, J.M., Finn, K.T., Doros, G., Blade, J. \& Skinner, M. (2011) Outcome of AL amyloidosis after high-dose melphalan and autologous stem cell transplantation: long-term results in a series of 421 patients. Blood, 118, 4346-4352.

Comenzo, R.L. \& Gertz, M.A. (2002) Autologous stem cell transplantation for primary systemic amyloidosis. Blood, 99, 4276-4282.

Comenzo, R.L., Vosburgh, E., Simms, R.W., Bergethon, P., Sarnacki, D., Finn, K., Dubrey, S., Faller, D.V., Wright, D.G., Falk, R.H. \& Skinner, M. (1996) Dose-intensive melphalan with blood stem cell support for the treatment of AL amyloidosis: one-year follow-up in five patients. Blood, 88, 2801-2806.

D'Souza, A., Dispenzieri, A., Wirk, B., Zhang, M.J., Huang, J., Gertz, M.A., Kyle, R.A., Kumar, S., Comenzo, R.L., Peter Gale, R., Lazarus, H.M., Savani, B.N., Cornell, R.F., Weiss, B.M., Vogl, D.T., Freytes, C.O., Scott, E.C., Landau, H.J., Moreb, J.S., Costa, L.J., Ramanathan, M., Callander, N.S., Kamble, R.T., Olsson, R.F., Ganguly, S., Nishihori, T., Kindwall-Keller, T.L., Wood, W.A., Mark, T.M. \& Hari, P. (2015) Improved Outcomes After Autologous Hematopoietic Cell Transplantation for Light Chain Amyloidosis: A Center for International Blood and Marrow Transplant Research Study. J Clin Oncol, 33, 3741-3749.

Dispenzieri, A., Gertz, M.A., Kyle, R.A., Lacy, M.Q., Burritt, M.F., Therneau, T.M., Greipp, P.R., Witzig, T.E., Lust, J.A., Rajkumar, S.V., Fonseca, R., Zeldenrust, S.R., McGregor, C.G. \& Jaffe, A.S. (2004) Serum cardiac troponins and N-terminal pro-brain natriuretic peptide: a staging system for primary systemic amyloidosis. J Clin Oncol, 22, 3751-3757.

Gertz, M.A., Comenzo, R., Falk, R.H., Fermand, J.P., Hazenberg, B.P., Hawkins, P.N., Merlini, G., Moreau, P., Ronco, P., Sanchorawala, V., Sezer, O., Solomon, A. \& Grateau, G. (2005) Definition of organ involvement and treatment response in immunoglobulin light chain amyloidosis (AL): a consensus opinion from the 10th International Symposium on Amyloid and Amyloidosis, Tours, France, 18-22 April 2004. Am J Hematol, 79, 319-328.

Gertz, M.A., Lacy, M.Q., Dispenzieri, A., Gastineau, D.A., Chen, M.G., Ansell, S.M., Inwards, D.J., Micallef, I.N., Tefferi, A. \& Litzow, M.R. (2002) Stem cell transplantation for the management of primary systemic amyloidosis. Am J Med, 113, 549-555.

Gertz, M.A., Lacy, M.Q., Dispenzieri, A., Kumar, S.K., Dingli, D., Leung, N., Hogan, W.J., Buadi, F.K. \& Hayman, S.R. (2013) Refinement in patient selection to reduce treatment-related mortality from autologous stem cell transplantation in amyloidosis. Bone Marrow Transplant, 48, 557-561.

Girnius, S., Seldin, D.C., Skinner, M., Finn, K.T., Quillen, K., Doros, G. \& Sanchorawala, V. (2009) Hepatic response after high-dose melphalan and stem cell transplantation in patients with AL amyloidosis associated liver disease. Haematologica, 94, 1029-1032.

Goodman, H.J., Gillmore, J.D., Lachmann, H.J., Wechalekar, A.D., Bradwell, A.R. \& Hawkins, P.N. (2006) Outcome of autologous stem cell transplantation for AL amyloidosis in the UK. $\mathrm{Br} \mathrm{J}$ Haematol, 134, 417-425.

Jaccard, A., Moreau, P., Leblond, V., Leleu, X., Benboubker, L., Hermine, O., Recher, C., Asli, B., Lioure, B., Royer, B., Jardin, F., Bridoux, F., Grosbois, B., Jaubert, J., Piette, J.C., Ronco, P., Quet, F., Cogne, M., Fermand, J.P., Myelome, A. \& Intergroupe Francophone du Myelome, I. (2007) High-dose melphalan versus melphalan plus dexamethasone for AL amyloidosis. $N$ Engl J Med, 357, 1083-1093.

Kumar, S., Dispenzieri, A., Lacy, M.Q., Hayman, S.R., Buadi, F.K., Colby, C., Laumann, K., Zeldenrust, S.R., Leung, N., Dingli, D., Greipp, P.R., Lust, J.A., Russell, S.J., Kyle, R.A., Rajkumar, S.V. \& Gertz, M.A. (2012) Revised prognostic staging system for light chain amyloidosis incorporating cardiac biomarkers and serum free light chain measurements. $J$ Clin Oncol, 30, 989-995. 
Manwani, R., Hegenbart, U., Mahmood, S., Sachchithanantham, S., Kyriakou, C., Yong, K., Popat, R., Rabin, N., Whelan, C., Dittrich, T., Kimmich, C., Hawkins, P., Schonland, S. \& Wechalekar, A. (2018) Deferred autologous stem cell transplantation in systemic AL amyloidosis. Blood Cancer J, 8, 101.

Migrino, R.Q., Mareedu, R.K., Eastwood, D., Bowers, M., Harmann, L. \& Hari, P. (2009) Left ventricular ejection time on echocardiography predicts long-term mortality in light chain amyloidosis. J Am Soc Echocardiogr, 22, 1396-1402.

Moreau, P., Leblond, V., Bourquelot, P., Facon, T., Huynh, A., Caillot, D., Hermine, O., Attal, M., Hamidou, M., Nedellec, G., Ferrant, A., Audhuy, B., Bataille, R., Milpied, N. \& Harousseau, J.L. (1998) Prognostic factors for survival and response after high-dose therapy and autologous stem cell transplantation in systemic AL amyloidosis: a report on 21 patients. $\mathrm{Br} \mathrm{J}$ Haematol, 101, 766-769.

Muchtar, E. \& Gertz, M.A. (2017) Improved outcomes for newly diagnosed AL amyloidosis between 2000 and 2014: cracking the glass ceiling of early death. Blood, 129, 2111-2119.

Oke, O., Sethi, T., Goodman, S., Phillips, S., Decker, I., Rubinstein, S., Concepcion, B., Horst, S., Jagasia, M., Kassim, A., Harrell, S.L., Langone, A., Lenihan, D., Rawling, K.T., Slosky, D. \& Cornell, R.F. (2017) Outcomes from Autologous Hematopoietic Cell Transplantation versus Chemotherapy Alone for the Management of Light Chain Amyloidosis. Biol Blood Marrow Transplant, 23, 1473-1477.

Pinney, J.H., Smith, C.J., Taube, J.B., Lachmann, H.J., Venner, C.P., Gibbs, S.D., Dungu, J., Banypersad, S.M., Wechalekar, A.D., Whelan, C.J., Hawkins, P.N. \& Gillmore, J.D. (2013) Systemic amyloidosis in England: an epidemiological study. Br J Haematol, 161, 525-532.

Rezk, T., Gilbertson, J.A., Mangione, P.P., Rowczenio, D., Rendell, N., Canetti, D., Lachmann, H.J., Wechalekar, A.D., Bass, P., Hawkins, P.N., Bellotti, V., Taylor, G.W. \& Gillmore, J.D. (2019) The complementary role of histology and proteomics for diagnosis and typing of systemic amyloidosis. J Pathol Clin Res. doi 10.1002/cjp2.126.

Saba, N., Sutton, D., Ross, H., Siu, S., Crump, R., Keating, A. \& Stewart, A. (1999) High treatmentrelated mortality in cardiac amyloid patients undergoing autologous stem cell transplant. Bone Marrow Transplant, 24, 853-855.

Sanchorawala, V., Quillen, K., Sloan, J.M., Andrea, N.T. \& Seldin, D.C. (2011) Bortezomib and high-dose melphalan conditioning for stem cell transplantation for AL amyloidosis: a pilot study. Haematologica, 96, 1890-1892.

Sanchorawala, V., Sun, F. \& Quillen, K. (2015) Long-term outcome of patients with AL amyloidosis treated with high-dose melphalan and stem cell transplantation: 20-year experience. Blood 126, 2345-2347.

Sher, T. \& Gertz, M.A. (2017) Stem cell transplantation for immunoglobulin light chain amyloidosis. Curr Probl Cancer, 41, 129-137.

Sidiqi, M.H., Aljama, M.A., Buadi, F.K., Warsame, R.M., Lacy, M.Q., Dispenzieri, A., Dingli, D., Gonsalves, W.I., Kumar, S., Kapoor, P., Kourelis, T., Hogan, W.J. \& Gertz, M.A. (2018) Stem Cell Transplantation for Light Chain Amyloidosis: Decreased Early Mortality Over Time. J Clin Oncol, 36, 1323-1329.

Skinner, M., Sanchorawala, V., Seldin, D.C., Dember, L.M., Falk, R.H., Berk, J.L., Anderson, J.J., O'Hara, C., Finn, K.T., Libbey, C.A., Wiesman, J., Quillen, K., Swan, N. \& Wright, D.G. (2004) High-dose melphalan and autologous stem-cell transplantation in patients with AL amyloidosis: an 8-year study. Ann Intern Med, 140, 85-93.

Thidemann Andersen, K., Klausen, T., Abildgaard, N., Klarskov Andersen, M., Frost Andersen, N., Christian Frolund, U., Helleberg, C., Kjeldsen, E., Pedersen, P., Helm-Petersen, S., Svirskaite, A., Preiss, B. \& Gimsing, P. (2017) Causes of early death in multiple myeloma patients treated with high-dose therapy followed by autologous stem cell transplantation: A study based on the nationwide Danish Multiple Myeloma Registry. 92, E611-e614.

Venner, C.P., Gillmore, J.D., Sachchithanantham, S., Mahmood, S., Lane, T., Foard, D., Roussel, M., Rannigan, L., Gibbs, S., Pinney, J.H., Whelan, C.J., Lachmann, H.J., Hawkins, P.N. \& Wechalekar, A.D. (2014) Stringent patient selection improves outcomes in systemic lightchain amyloidosis after autologous stem cell transplantation in the upfront and relapsed setting. Haematologica, 99, e260-263. 
Wechalekar, A.D., Gillmore, J.D., Bird, J., Cavenagh, J., Hawkins, S., Kazmi, M., Lachmann, H.J., Hawkins, P.N., Pratt, G. \& Committee, B. (2015) Guidelines on the management of AL amyloidosis. Br J Haematol, 168, 186-206.

White, P.S., Phull, P., Brauneis, D., Sloan, J.M., Quillen, K., Sarosiek, S. \& Sanchorawala, V. (2018) High-dose melphalan and stem cell transplantation in AL amyloidosis with elevated cardiac biomarkers. Bone Marrow Transplant, 53, 1593-1595. 


\begin{tabular}{|c|c|c|c|c|c|c|c|}
\hline Variable & $\begin{array}{l}\text { All patients } \\
(n=264) \\
n(\%) / \text { median } \\
(\text { range })\end{array}$ & $\begin{array}{l}1994-2000 \\
(n=64) \\
n(\%) / \text { median } \\
(\text { range })\end{array}$ & $\begin{array}{l}2001-2006 \\
(n=44) \\
n(\%) / \text { median } \\
(\text { range })\end{array}$ & $\begin{array}{l}2007-2012 \\
(n=65) \\
n(\%) / \text { median } \\
(\text { range })\end{array}$ & $\begin{array}{l}2013-2018 \\
(n=91) \\
n(\%) / \text { median } \\
(\text { range })\end{array}$ & $\begin{array}{l}\text { P- } \\
\text { Kruskall- } \\
\text { Wallis /Chi- } \\
\text { square }\end{array}$ & $\begin{array}{l}\text { Trend } \\
\text { test }\end{array}$ \\
\hline $\begin{array}{l}\text { Age at time of ASCT } \\
\text { (years) }\end{array}$ & $57(30-70)$ & $53(34-66)$ & $53(30-67)$ & $60(40-68)$ & $58(38-70)$ & $<0.001$ & 0.002 \\
\hline Gender (male) & $147(55.7)$ & $37(58)$ & $23(52.3)$ & $37(56.9)$ & $50(54.9)$ & 0.943 & 0.605 \\
\hline $\begin{array}{l}\text { Diagnosis to ASCT } \\
\text { (months) }\end{array}$ & $12(0-263)$ & $7.5(0-70)$ & $13(1-76)$ & $14(4-263)$ & $13(1-157)$ & $<0.001$ & $<0.001$ \\
\hline $\begin{array}{l}\text { Performance Status } \\
0 \\
1 \\
2 \\
3 \\
4 \\
\end{array}$ & $\begin{array}{l}101(38.3) \\
121(45.8) \\
34(12.9) \\
7(2.7) \\
1(0.4)\end{array}$ & $\begin{array}{l}29(45.3) \\
17(26.6) \\
15(23.4) \\
3(4.7) \\
0\end{array}$ & $\begin{array}{l}22(50) \\
16(36.4) \\
4(9.1) \\
2(4.5) \\
0\end{array}$ & $\begin{array}{l}15(23.1) \\
43(66.2) \\
7(10.8) \\
0 \\
0\end{array}$ & $\begin{array}{l}35(38.5) \\
45(49.5) \\
8(8.8) \\
2(2.2) \\
1(1.1)\end{array}$ & 0.002 & 0.178 \\
\hline $\begin{array}{l}\text { Mayo Stage } \\
(\mathbf{n}=\text { evaluable }) \\
1 \\
2 \\
3\end{array}$ & $\begin{array}{l}(n=144) \\
63(43.8) \\
56(38.9) \\
25(17.4)\end{array}$ & $\begin{array}{l}(n=13) \\
6(46.2) \\
2(15.4) \\
5(38.5)\end{array}$ & $\begin{array}{l}(n=11) \\
3(27.2) \\
6(54.5) \\
2(18.2)\end{array}$ & $\begin{array}{l}(n=30) \\
13(43.3) \\
11(36.7) \\
6(20.0)\end{array}$ & $\begin{array}{l}(n=90) \\
41(45.6) \\
37(41.1) \\
12(13.3)\end{array}$ & 0.256 & 0.109 \\
\hline $\begin{array}{l}\text { Number of organs } \\
\text { involved (median) }\end{array}$ & $2(1-4)$ & $2(1-4)$ & $2(1-4)$ & $2(1-4)$ & $1(1-3)$ & $<0.001$ & $<0.001$ \\
\hline $\begin{array}{l}\text { Organ Involvement } \\
\text { Heart } \\
\text { Kidney } \\
\text { Liver } \\
\text { GI } \\
\text { Peripheral nerve } \\
\text { Autonomic nervous } \\
\text { system }\end{array}$ & $\begin{array}{l}85(32.2) \\
180(68.2) \\
52(19.7) \\
10(3.8) \\
21(8.0) \\
10(3.8)\end{array}$ & $\begin{array}{l}18(28.1) \\
43(67.2) \\
6(15.4) \\
0 \\
1(1.6) \\
0\end{array}$ & $\begin{array}{l}17(38.6) \\
35(79.5) \\
7(19.4) \\
4(9.1) \\
6(13.6) \\
1(2.3)\end{array}$ & $\begin{array}{l}18(27.7) \\
39(60) \\
2(3.1) \\
4(6.2) \\
7(10.8) \\
4(6.2)\end{array}$ & $\begin{array}{l}32(35.2) \\
64(70.3) \\
8(8.8) \\
2(2.2) \\
7(7.7) \\
5(5.5)\end{array}$ & $\begin{array}{l}0.514 \\
0.182 \\
\mathbf{0 . 0 3 0} \\
0.056 \\
0.101 \\
0.210\end{array}$ & $\begin{array}{l}0.785 \\
0.825 \\
<\mathbf{0 . 0 0 1} \\
0.719 \\
0.697 \\
0.188\end{array}$ \\
\hline $\begin{array}{l}\text { SFLC(mg/L) } \\
\text { (n=evaluable) } \\
\text { Lambda } \\
\text { Kappa }\end{array}$ & $(n=235)$ & $\begin{array}{l}(n=38) \\
57(0-4320) \\
10(1-5310) \\
\end{array}$ & $\begin{array}{l}(n=35) \\
49(1-5180) \\
16(0-6810)\end{array}$ & $\begin{array}{l}(n=65) \\
104(0-26702) \\
14(1-3040) \\
\end{array}$ & $\begin{array}{l}(n=91) \\
86(2-12800) \\
10(0-2211)\end{array}$ & $\begin{array}{l}0.515 \\
0.220 \\
\end{array}$ & $\begin{array}{l}0.470 \\
0.660\end{array}$ \\
\hline IVS (mm) & $11(7-20)$ & $11(7-20)$ & $12(8-16)$ & $11(8-16)$ & $11(8-19)$ & 0.257 & 0.645 \\
\hline $\begin{array}{l}\text { NT-proBNP (ng/L) } \\
(\mathrm{N}=\text { evaluable) }\end{array}$ & $\begin{array}{l}(n=243) \\
318(1-92773)\end{array}$ & $\begin{array}{l}(n=51) \\
574(8-92773)\end{array}$ & $\begin{array}{l}(n=38) \\
364(1-23756)\end{array}$ & $\begin{array}{l}(n=64) \\
262(25-5636)\end{array}$ & $\begin{array}{l}(n=90) \\
385(17-22025)\end{array}$ & 0.455 & 0.115 \\
\hline $\begin{array}{l}\text { Baseline creatinine } \\
(\mu \mathrm{mol} / \mathrm{l})\end{array}$ & $78(34-654)$ & $85(44-500)$ & $84(53-480)$ & $75(34-654)$ & $72(42-490)$ & $<0.001$ & $<0.001$ \\
\hline Albumin $(g / l)$ & $33(12-52)$ & $31(12-52)$ & $35(17-49)$ & $39(17-51)$ & $32(16-49)$ & 0.004 & 0.027 \\
\hline Proteinuria $(\mathrm{g} / 24 \mathrm{hr})$ & $3.8(0-20)$ & $4.2(0-20)$ & $4.2(0.1-15)$ & $1.15(0-12)$ & $5(0-20)$ & 0.012 & 0.921 \\
\hline Bilirubin $(\mu \mathrm{mol} / \mathrm{l})$ & $7(1-48)$ & $8(2-48)$ & $7(4-12)$ & $7(1-16)$ & $6(2-27)$ & 0.004 & 0.001 \\
\hline ALP (IU/l) & $80(36-986)$ & $90(36-986)$ & $92(41-491)$ & $71(43-306)$ & $76(37-795)$ & 0.002 & 0.003 \\
\hline $\begin{array}{l}\text { ASCT line of } \\
\text { treatment }\end{array}$ & $2(1-5)$ & $1(1-2)$ & $2(1-4)$ & $2(1-4)$ & $2(1-5)$ & $<0.001$ & $<0.001$ \\
\hline $\begin{array}{l}\text { Pre-ASCT regimen } \\
\text { Thalidomide } \\
\text { Velcade } \\
\text { Melphalan } \\
\text { Other } \\
\text { Missing/ not given } \\
\end{array}$ & $\begin{array}{l}58(36.3) \\
83(51.8) \\
6(3.8) \\
13(4.9) \\
104(39.4) \\
\end{array}$ & $\begin{array}{l}\text { Missing/not } \\
\text { given }\end{array}$ & $\begin{array}{l}4(14.8) \\
16(59.3) \\
2(7.4) \\
5(18.5) \\
17(38.6)\end{array}$ & $\begin{array}{l}39(60) \\
12(18.8) \\
7(15.6) \\
6(9.4) \\
0 \\
\end{array}$ & $\begin{array}{l}15(16.5) \\
55(60.4) \\
22(24.2) \\
3(3.3) \\
0\end{array}$ & $\begin{array}{l}<0.001 \\
<0.001\end{array}$ & $\begin{array}{l}0.002 \\
<0.001\end{array}$ \\
\hline TRM (n (\%)) & $23(8.7 \%)$ & $12(18.8)$ & $6(13.6)$ & $4(6.2)$ & $1(1.1)$ & 0.001 & $<0.001$ \\
\hline $\begin{array}{l}\text { Median OS post } \\
\text { ASCT (months) }\end{array}$ & 87 & 60 & 60 & Not reached & Not reached & & \\
\hline TTNT (months) & $24(0-187)$ & $87(2-187)$ & $18(3-132)$ & $28(0-68)$ & $15(0-45)$ & & 0.009 \\
\hline
\end{tabular}

Table 1: patient baseline characteristics and a comparison of variables across the time cohorts.

ASCT $=$ autologous stem cell transplant; GI= gastrointestinal; IVS= left ventricular septum; ALP= alkaline phosphatase; NT-proBNP= N- terminal B natriuretic peptide; $\mathrm{SFLC}=$ serum free light chain; $\mathrm{TRM}=$ transplant related mortality; OS=overall survival; TTNT= time to next treatment. 
Table 2: Number $(\%)$ with haematological response to autologous stem cell transplant, determined at six months.

\begin{tabular}{|c|c|c|c|c|c|c|}
\hline Response (n=evaluable) & $\begin{array}{l}\text { All patients } \\
(n=264)\end{array}$ & $\begin{array}{l}1994-2000 \\
(n=64)\end{array}$ & $\begin{array}{l}2001-2006 \\
(n=44)\end{array}$ & $\begin{array}{l}2007-2012 \\
(n=65)\end{array}$ & $\begin{array}{l}\text { 2013-2018 } \\
(n=91)\end{array}$ & $\begin{array}{l}\text { Trend } \\
\text { Mantel- } \\
\text { Haenszel/ } \\
\text { Spearman }\end{array}$ \\
\hline $\begin{array}{l}\text { Haematological response } \\
\text { Complete response } \\
\text { Very good partial response } \\
\text { Partial response } \\
\text { No response } \\
\text { Progressive disease }\end{array}$ & $\begin{array}{l}(n=236) \\
122(52.4) \\
40(17.2) \\
59(25.3) \\
10(4.3) \\
5(2.1)\end{array}$ & $\begin{array}{l}(n=46) * \\
32(69.6) \\
3(6.5) \\
9(19.6) \\
2(4.3) \\
0(0)\end{array}$ & $\begin{array}{l}(n=35) \\
13(37.1) \\
4(11.4) \\
16(45.7) \\
2(5.7) \\
0(0)\end{array}$ & $\begin{array}{l}(n=65) \\
31(47.7) \\
11(16.9) \\
23(35.4) \\
0(0) \\
0(0)\end{array}$ & $\begin{array}{l}(n=90) \\
46(51.1) \\
22(24.4) \\
11(12.2) \\
6(6.7) \\
5(5.6)\end{array}$ & 0.348 \\
\hline $\begin{array}{l}\text { Cardiac response } \\
\text { Response } \\
\text { No response } \\
\text { Progression }\end{array}$ & $\begin{array}{l}(n=46 / 85) \\
28(60.9) \\
10(21.7) \\
8(17.4)\end{array}$ & $* *$ & $* *$ & $\begin{array}{l}(n=16 / 18) \\
8(50) \\
5(31.3) \\
3(18.8)\end{array}$ & $\begin{array}{l}(n=2732) \\
18(66.7) \\
4(14.8) \\
5(18.5)\end{array}$ & 0.608 \\
\hline $\begin{array}{l}\text { Renal response } \\
\text { Response } \\
\text { No response } \\
\text { Progression }\end{array}$ & $\begin{array}{l}(n=134 / 180) \\
101(76.0) \\
18(13.5) \\
14(10.5)\end{array}$ & $\begin{array}{l}(n=22 / 43) \\
9(40.9) \\
10(45.5) \\
3(13.6)\end{array}$ & $\begin{array}{l}(n=26 / 35) \\
11(42.3) \\
11(42.3) \\
4(15.4)\end{array}$ & $\begin{array}{l}(n=33 / 39) \\
17(51.5) \\
10(30.3) \\
6(18.2)\end{array}$ & $\begin{array}{l}(n=53 / 64) \\
38(71.7) \\
14(26.4) \\
1(1.9)\end{array}$ & 0.032 \\
\hline $\begin{array}{l}\text { Liver response } \\
\text { Response } \\
\text { No response } \\
\text { Progression }\end{array}$ & $\begin{array}{l}(n=32 / 52) \\
7(13.5) \\
19(61.3) \\
6(19.4)\end{array}$ & $\begin{array}{l}(n=10 / 23) \\
2(20) \\
6(60) \\
2(20)\end{array}$ & $\begin{array}{l}(n=8 / 15) \\
1(12.5) \\
5(62.5) \\
2(25)\end{array}$ & $\begin{array}{l}(n=5 / 5) \\
0(0) \\
3(60) \\
2(40)\end{array}$ & $\begin{array}{l}(n=9 / 10) \\
4(44.4) \\
5(55.6) \\
0(0)\end{array}$ & 0.065 \\
\hline
\end{tabular}

* Assessed by SFLC in 59\% $(n=27 / 46)$ and paraprotein in $41 \%(n=19 / 46)$

** Cardiac response assessment not possible due to lack of NT-proBNP levels prior to 2007. 
Table 3: Univariable Cox regression analysis of overall survival for the entire cohort $(n=264)$

\begin{tabular}{|c|c|c|c|}
\hline Variable & $\begin{array}{l}\text { Hazard } \\
\text { Ratio }\end{array}$ & $95 \% \mathrm{CI}$ & $P$ value \\
\hline Age at time of ASCT (years) & 0.991 & $0.965-1.018$ & 0.520 \\
\hline Gender (male) & 1.143 & $0.740-1.764$ & 0.548 \\
\hline Diagnosis to ASCT (months) & 1.007 & $0.998-1.016$ & 0.146 \\
\hline $\begin{array}{l}\text { Performance Status (compared to } 0)(n=264) \\
1 \\
2,3 \text { or } 4\end{array}$ & $\begin{array}{l}0.640 \\
2.647\end{array}$ & $\begin{array}{l}0.389-1.051 \\
1.466-4.781\end{array}$ & $\begin{array}{l}0.078 \\
\mathbf{0 . 0 0 1}\end{array}$ \\
\hline $\begin{array}{l}\text { Mayo Stage (compared to 1) }(n=144) \\
2 \text { or } 3\end{array}$ & 2.620 & $1.038-6.613$ & 0.042 \\
\hline $\begin{array}{l}\text { LC type }(\mathbf{n}=\mathbf{2 3 5}) \\
\text { kappa/lambda }\end{array}$ & 1.263 & $0.737-2.163$ & 0.396 \\
\hline Number of organs involved (median) & 1.592 & $1.270-1.994$ & $<0.001$ \\
\hline $\begin{array}{l}\text { Amyloid load on SAP scintigraphy }(\mathbf{n}=238) \\
\text { Equivocal } \\
\text { Small } \\
\text { Moderate } \\
\text { large }\end{array}$ & $\begin{array}{l}1.335 \\
0.832 \\
1.428 \\
1.950\end{array}$ & $\begin{array}{l}0.560-3.180 \\
0.430-1.610 \\
0.701-2.911 \\
0.960-3.961\end{array}$ & $\begin{array}{l}0.514 \\
0.586 \\
0.327 \\
0.065\end{array}$ \\
\hline $\begin{array}{l}\text { Organ Involvement }(\mathbf{n}=\mathbf{2 6 4}) \\
\text { Heart } \\
\text { Kidney } \\
\text { Liver } \\
\text { GI } \\
\text { Peripheral nervous system } \\
\text { Autonomic nervous system }\end{array}$ & $\begin{array}{l}1.565 \\
1.535 \\
2.287 \\
2.810 \\
0.475 \\
0.631\end{array}$ & $\begin{array}{l}1.008-2.429 \\
0.935-2.521 \\
1.261-4.147 \\
1.207-6.543 \\
0.190-1.188 \\
0.369-1.080\end{array}$ & $\begin{array}{l}\mathbf{0 . 0 4 6} \\
0.090 \\
\mathbf{0 . 0 0 6} \\
\mathbf{0 . 0 1 7} \\
0.112 \\
0.093\end{array}$ \\
\hline IVS (mm) & 1.204 & $1.083-1.338$ & 0.001 \\
\hline Log-NT-proBNP & 1.811 & $1.269-2.584$ & 0.001 \\
\hline Log-creatinine $(\mu \mathrm{mol} / \mathrm{l})$ & 3.168 & $1.201-8.359$ & 0.020 \\
\hline Albumin $(\mathrm{g} / \mathrm{l})$ & 0.980 & $0.956-1.005$ & 0.113 \\
\hline Proteinuria (g/24hr) & 1.026 & $0.976-1.078$ & 0.314 \\
\hline Bilirubin $(\mu \mathrm{mol} / \mathrm{l})$ & 1.004 & $0.940-1.072$ & 0.912 \\
\hline Abnormal ALP (> 129IU/l) & 1.927 & $1.174-3.165$ & $<0.010$ \\
\hline $\begin{array}{l}\text { ASCT line of treatment (compared to 1) }(n=264) \\
2 / 3 / 4\end{array}$ & 0.600 & $0.381-0.947$ & 0.028 \\
\hline $\begin{array}{l}\text { Pre-ASCT regimen } \\
\text { Thalidomide }(n=58) \\
\text { Velcade }(n=83)\end{array}$ & $\begin{array}{l}0.581 \\
1.236\end{array}$ & $\begin{array}{l}0.303-1.115 \\
0.655-2.333\end{array}$ & $\begin{array}{l}0.102 \\
0.513\end{array}$ \\
\hline $\begin{array}{l}\text { Conditioning (compared to Melphalan 200) } \\
\text { Dose reduced melphalan }(\mathrm{n}=80)\end{array}$ & 1.263 & $0.803-1.987$ & 0.313 \\
\hline
\end{tabular}

ASCT = autologous stem cell transplant; LC= light chain; IVS= left ventricular septum; NT-proBNP= Nterminal pro-B natriuretic peptide; $\mathrm{ALP}=$ alkaline phosphatase. 
Table 4: Multivariable Cox regression analysis of overall survival for the entire cohort

\begin{tabular}{|l|l|l|l|}
\hline & $\begin{array}{l}\text { Hazard } \\
\text { ratio }\end{array}$ & $\mathbf{9 5 \%}$ CI & P-value \\
\hline Time cohort & & & \\
$2001-2006$ & 2.73 & $0.52-14.41$ & 0.238 \\
$2007-2012$ & 0.48 & $0.10-2.33$ & 0.365 \\
$2013-2018$ & 0.16 & $0.03-0.77$ & 0.023 \\
\hline Performance status & 3.38 & $1.12-10.20$ & $\mathbf{0 . 0 3 0}$ \\
\hline Abnormal ALP & 6.96 & $1.90-25.51$ & $\mathbf{0 . 0 0 3}$ \\
\hline Mayo stage 2 or 3 & 5.49 & $1.62-18.66$ & $\mathbf{0 . 0 0 6}$ \\
\hline Creatinine & 1.60 & $0.32-8.01$ & 0.565 \\
\hline No. organs involved & 0.58 & $0.30-1.14$ & 0.116 \\
\hline GI involvement & 5.00 & $0.41-61.78$ & 0.209 \\
\hline ASCT line treatment & 0.75 & $0.21-2.66$ & 0.660 \\
\hline
\end{tabular}

$\mathrm{ALP}=$ alkaline phosphatase $; \mathrm{GI}=$ gastrointestinal $; \mathrm{ASCT}=$ autologous stem cell transplant $\mathrm{CI}=$ confidence interval 
Table 5: Comparison with contemporary data. All values are percentages, unless otherwise specified.

Haematology response $=$ partial response or better; $\mathrm{TRM}=$ transplant related mortality; $\mathrm{OS}=$ overall survival; UK= United Kingdom

\begin{tabular}{|c|c|c|c|c|}
\hline & Cohort 1 & Cohort 2 & Cohort 3 & Cohort 4 \\
\hline \multicolumn{5}{|l|}{ TRM } \\
\hline D'Souza et al. (2015) & 20 & 11 & 5 & \\
\hline Sidiqi et.al. (2018) & 14.5 & 8.6 & \multicolumn{2}{|l|}{2.4} \\
\hline Sanchorawala (2015) & 14.0 & 8.4 & \multicolumn{2}{|l|}{7.5} \\
\hline Current UK cohort & 18.8 & 13.6 & 6.2 & 1.1 \\
\hline \multicolumn{5}{|l|}{5 yr OS } \\
\hline D'Souza et al. (2015) & 55 & 61 & 77 & NA \\
\hline Sidiqi et.al. (2018) (median) & 75 months & 120 months & \multicolumn{2}{|l|}{ Not reached } \\
\hline Sanchorawala (2015) (median) & 57 months & 90 months+ & \multicolumn{2}{|l|}{92 months } \\
\hline Current UK cohort & 45 & 51 & 83 & 90 \\
\hline \multicolumn{5}{|l|}{ Haematologic response } \\
\hline D’Souza et al. (2015) & NA & 68 & 80 & 84 \\
\hline Sidiqi et.al. (2018) & 69 & 79 & 84 & \\
\hline Sanchorawala (2015) & NA & NA & NA & \\
\hline Current UK cohort & 96 & 94 & 100 & 88 \\
\hline
\end{tabular}

*D’Souza et.al (2015) cohorts 1: 1995-2000; cohort 2: 2001-2006; cohort 3: 2007-2012

** Sidiqi et. al (2018) cohorts: 1: 1996-2002, cohort 2: 2003-2009; cohort 3: 2010-2016

*** Sanchorwala (2015) cohorts: 1: 1994-2000, cohort 2: 2000-2009, cohort 3: 1994-2014

**** Current UK cohort: 1: 1994-2000; cohort 2: 2001-2006; cohorts 3: 2007-2012; cohort 4: 2013-2018. 


\section{Figure legends}

Fig. 1: Overall survival by date of autologous stem cell transplant: blue line=1994-2000, green line $=2001-2006$, red $=2007-2012$, yellow $=2013-2018$.

Fig. 2: Overall survival by haematological response at 6 months: blue line $=$ complete response and very good partial response, red $=$ partial response, no response and progressive disease, $\mathrm{P}=<0.007$.

Fig. 3: Time to next treatment by haematological response: blue $=$ complete response and very good partial response, red $=$ partial response and no response, $\mathrm{P}=<0.0001$. 
Figure 1

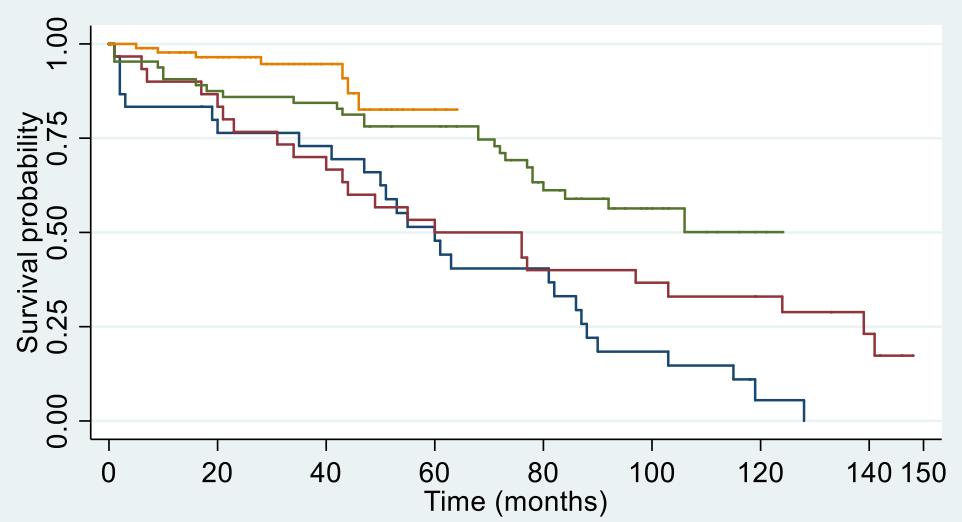

Number at risk

$\begin{array}{llllllllllllllll}1994-2000 & 30 & (6) & 23 & (2) & 21 & (6) & 14 & (3) & 11 & (6) & 5 & (4) & 1 & (0) & 0(0) 0\end{array}$

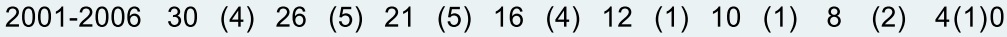

2007-2012 64 (8) 56 (2) 54 (4) 48 (8) 30 (3) 14 (1) 3 (0) $0(0) 0$

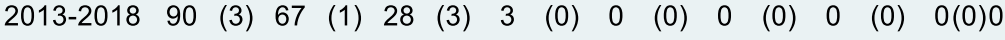

Cohort $=1994-2000$

Cohort $=2001-2006$

Cohort $=2007-2012$

Cohort $=2013-2018$

\section{Figure 2}

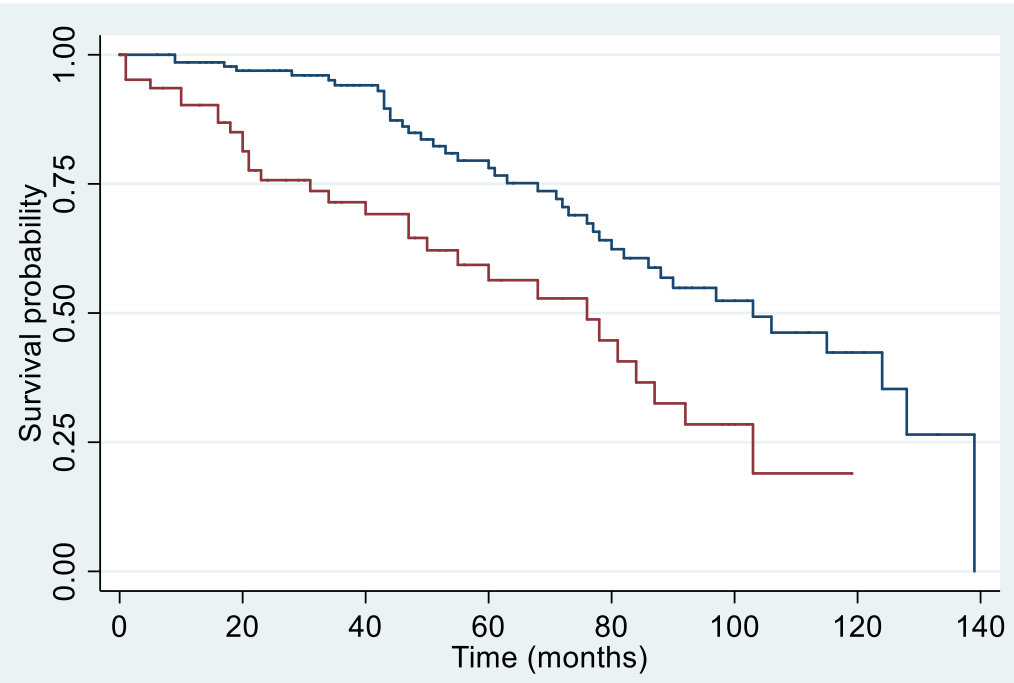

Number at risk

CR, VGPR 137 (4) 119 (3) 86 (12) 55 (10) $37 \quad$ (6) 19 (3) 8 (3) 0
$P R, S D, P D$
$62(9)$
(4) 5
(1) 0
(0) 0

$\begin{array}{cccccc} & 119 & (3) & 86 & (12) & 55 \\ \text { (9) } & 46 & (7) & 31 & (5) & 20\end{array}$ 


\section{Figure 3}

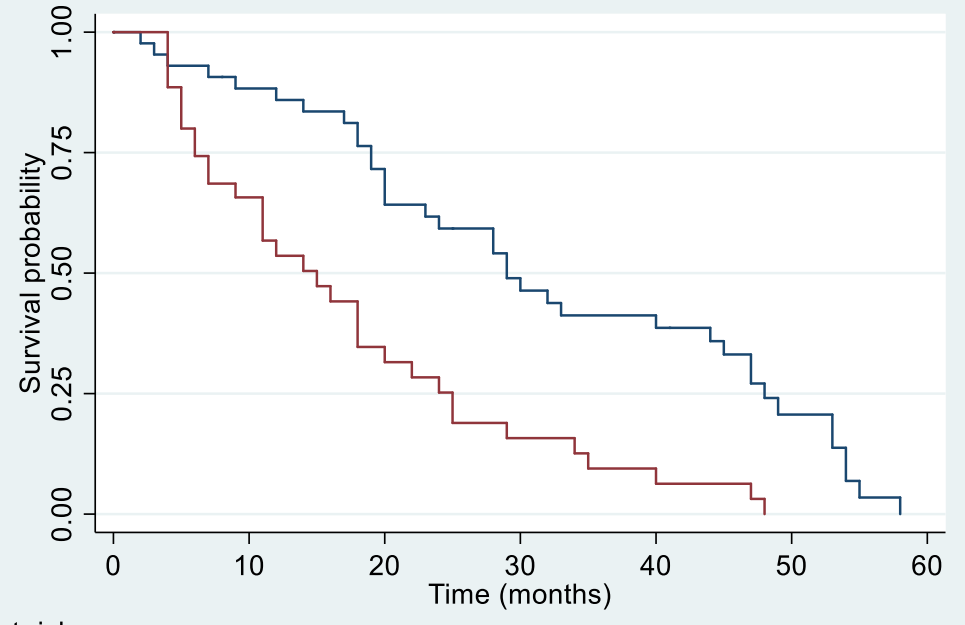

Number at risk

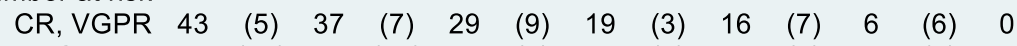
$\mathrm{PR}, \mathrm{SD}, \mathrm{PD} \quad 35$

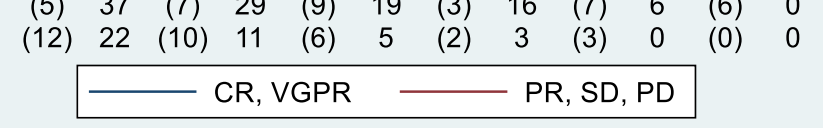

